\title{
ANALISIS PERBEDAAN PRODUKTIVITAS UKURAN KAPAL DAN PENGARUHNYA TERHADAP HASIL TANGKAPAN IKAN (STUDI EMPIRIS NELAYAN GILNET DI PELABUHAN PERIKANAN SAMUDERA CILACAP)
}

\author{
Indra Sukma Yulianto, Rusmusi Indranjoto MP, dan Suharno \\ Universitas Jenderal Soedirman \\ Email: idrsukma@gmail.com,rusmusi.indranjoto@unsoed.ac.id dan suharno@unsoed.ac.id
}

\begin{abstract}
This study analyzes the productivity of ships between vessel size under 5 GT and sizes 21-30 GT and analyzes the effect of variables on vessel size, time spent fishing, number of fishers, and fuel usage on fishing results. This study using quantitative descriptive methods; respondents were 86 fishers. Data collection using questionnaires, analysis techniques using multiple linear regression. The results showed the productivity level of ships under 5 GT was $2.07 \%$, smaller than the productivity level of ships of 20-30 GT was 6.95\%. The vessel size and the fuel usage have a significant positif effect on the catch of vessels under 5 GT, while the vessel size, fuel usage, and the number of fishers have a significant positif effect on the catch of ships measuring 20-30 GT. The implication for fishers in Cilacap Marine Port Area pays more attention to cost allocation and fishing locations to increase catches and productivity.
\end{abstract}

Keyword: Productivity, Catch, Vessel size, Time spent fishing, Fuel Usage, and Number of fishers.

\begin{abstract}
Abstrak
Penelitian ini bertujuan untuk menganalisis produktivitas kapal antara kapal ukuran di bawah 5 GT dan ukuran 21-30 GT serta menganalisis pengaruh variabel ukuran kapal, lamanya waktu melaut, jumlah awak kapal, dan penggunaan BBM terhadap hasil penangkapan ikan. Dalam penelitian ini menggunakan metode deskriptif kuantitatif, responden dalam penelitian ini berjumlah 86 orang nelayan. Teknik pengumpulan data menggunakan kuesioner, teknik analisis menggunakan teknik analisis regresi linier berganda. Hasil penelitian menunjukkan bahwa tingkat produktivitas kapal di bawah 5 GT adalah 2,07\%, lebih kecil dari tingkat produktivitas kapal 20-30 GT yang sebesar 6,95\%. Kemudian ukuran kapal dan penggunaan BBM berpengaruh positif signifikan terhadap hasil tangkapan kapal di bawah 5 GT, sedangkan ukuran kapal, penggunaan BBM, dan jumlah awak kapal berpengaruh positif signifikan terhadap hasil tangkapan kapal berukuran 20-30 GT. Implikasinya, nelayan di Kawasan Pelabuhan Perikanan Laut Cilacap lebih memperhatikan alokasi biaya dan pemilihan lokasi penangkapan untuk meningkatkan hasil tangkapan dan produktivitas.
\end{abstract}

Kata Kunci: Produktivitas, Hasil Tangkapan, Ukuran kapal, Lama Melaut, Penggunaan $B B M$, dan Jumlah ABK. 


\section{PENDAHULUAN}

Indonesia adalah negara yang berbentuk negara kepulauan, Indonesia memiliki predikat sebagai negara kepulauan terbesar di dunia. Laut Indonesia meliputi 70 persen dari luas teritorial wilayah Indonesia dengan total panjang garis pantai sepanjang \pm 95 $181 \mathrm{~km}$ (Durand, 2010). Indonesia memiliki sumberdaya alam yang melimpah yang dapat di manfaatkan untuk memenuhi kebutuhan masyarakat, berdasarkan 13 sektor kelautan salah satu sektor sumberdaya yang dapat dijadikan penggerak utama perekonomian nasional adalah sektor prikanan (Suharno, \& Widayati, T., 2015).

Provinsi Jawa Tengah salah satu provinsi Pulau Jawa yang memiliki hasil tangkapan yang terdiri dari perikanan tangkap laut dan perikanan tangkap perairan umum yang mampu di kembangkan lebih baik lagi (Ardiansyah, dkk 2019; Susilowati, dkk 2018). Potensi perikanan tangkap laut yang tersebar di perairan Jawa Tengah kurang lebih 1.873 .530 ton/tahun yang mencakup Laut Jawa sekitar 796.640 ton/tahun dan Samudera Indonesia sekitar 1.076.890 ton/tahun.

Cilacap merupakan kota yang paling tinggi hasil tangkap ikan lautnya untuk kota yang berbatasan langsung dengan Samudera Hindia. Kota Cilacap sendiri memiliki tiga pelabuhan. Pelabuhan yang ada di Cilacap adalah Pelabuhan Perikanan Samudera Cilacap (PPSC), Pelabuhan Tanjung Intan, dan Pelabuhan Sleko. Peneliti memilih melakukan penelitian di PPSC karena sesuai dengan persetujuan Menteri Pendayagunaan Aparatur Negara No 86/M/PAN/4/2001 tanggal 4 April 2001 pelabuhan PPSC merupakan pelabuhan perikanan. Cilacap merupakan kota yang sebagian masyarakatnya bermata pencaharian sebagai nelayan. Tahun 2018 tercatat bahwa masyarakat tepi pantai Kota Cilacap yang bermata pencaharian sebagai nelayan di Kawasan PPSC sebanyak 5733 orang (Pribadi, 2018). Selain dijual secara langsung, hasil tangkapan juga ada yang diolah terlebih dahulu menjadi olahan ikan asin.

Pada proses penangkapan ikan laut, nelayan menggunakan kapal tangkap ikan sebagai salah satu faktor produksi (Suharno, dkk 2018). Kapal yang digunakan oleh nelayan Kawasan PPSC dibedakan menjadi dua jenis kapal tangkap ikan, yaitu jenis kapal motor (Inboard Motor) dan motor tempel (Outboard Motor). Kapal motor merupakan kapal yang sudah memasang motor secara permanen di dalam kapal, sedangkan kapal tempel merupakan kapal yang menggunakan motor yang tidak di pasang secara permanen sehingga motor pada kapal bisa di lepas dari kapal. Kapal dengan ukuran di bawah 5 GT merupakan kapal tempel atau kapal yang menggunakan mesin yang dapat di lepas dari kapal (Outboard Motor). Sedangkan untuk kapal dengan ukuran 5 GT ke atas sudah menggunakan mesin kapal yang permanen terpasang di dalam kapal (Inboard Motor). Berikut ini disajikan tabel 1 data berupa Jenis dan ukuran kapal.

Tabel 1. Jenis Dan Ukuran Kapal Tangkap Ikan Laut Di Kawasan PPSC

\begin{tabular}{cc}
\hline Jenis kapal & Ukuran kapal (GT) \\
\hline Outboard & $<5 \mathrm{GT}$ \\
motor & $5-10 \mathrm{GT}$ \\
& $11-20 \mathrm{GT}$ \\
Inboard motor & $21-30 \mathrm{GT}$ \\
& $31-50 \mathrm{GT}$ \\
& $50-200 \mathrm{GT}$ \\
\hline
\end{tabular}

Sumber: Pelabuhan Perikanan Samudera Hindia (2019)

Dalam perjalanannya, hasil tangkap nelayan di Kawasan PPSC mengalami fluktuasi dari tahun ke tahun. Berikut ini adalah hasil tangkap ikan tahun 2014 sampai tahun 2018, ditampilkan pada tabel 2. 
Tabel 2. Hasil Tangkap Ikan Laut Tahun 2014 - 2018 di Kawasan PPSC.

\begin{tabular}{crc}
\hline Tahun & $\begin{array}{c}\text { Hasil } \\
\text { Tangkap } \\
\text { Ikan (Ton) }\end{array}$ & $\begin{array}{c}\text { Prosentase } \\
(\%)\end{array}$ \\
\hline 2014 & $5.737,65$ & \\
2015 & $13.317,71$ & 2,3 \\
& $\%$ \\
2016 & $7.966,55$ & $0,6 \%$ \\
2017 & $11.840,11$ & $1,5 \%$ \\
2018 & $15.216,85$ & $1,3 \%$ \\
\hline
\end{tabular}

Sumber: Pelabuhan Perikanan Samudera Hindia (2019)

Berdasarkan tabel 2 hasil tangkap ikan paling sedikit ada di tahun 2014 yaitu sebesar 5.737,65 ton. Hasil tangkap ikan pada tahun berikutnya mengalami peningkatan sebesar $132,11 \%$ produksi pada tahun 2015 sebesar 13,317,71 ton dan di tahun berikutnya yaitu pada tahun 2016 hasil tangkap ikan mengalami penurunan sebesar 5.351,16 ton, hasil tangkap pada tahun tersebut hanya sebesar $7.966,55$ ton. Tahun 2017 hasil tangkap ikan laut mengalami peningkatan sebesar $3.873,56$ ton, dan pada tahun berikutnya hasil tangkap ikan kembali mengalami peningkatan, dan pada tahun 2018 hasil tangkap ikan berada pada puncaknya hasil tangkap ikan lautnya sebesar 15.216,85 ton.

Hasil tangkap pada tabel 3 merupakan hasil tangkap dari berbagai jenis ukuran kapal, tampilan berikut ini akan lebih di spesifikasi pada hasil tangkap ikan dari tahun 2014 sampai dengan tahun 2018 menjadi dua jenis ukuran kapal, jenis ukuran kapal yang dimaksud adalah kapal ukuran di bawah 5 GT dan kapal ukuran 20-30 GT. Berikut ini adalah hasil tangkap dari kapal dengan ukuran kapal di bawah 5 GT dan ukuran 21-30 GT pada tabel 3.
Tabel 3. Hasil Tangkap Ikan Laut Berdasarkan Ukuran Kapal Di Bawah 5 GT dan Ukuran 21-30 GT Kawasan PPSC.

\begin{tabular}{ccc}
\hline \multirow{2}{*}{ Tahun } & \multicolumn{2}{c}{ Hasil tangkap ikan laut } \\
\cline { 2 - 3 } & $<\mathbf{5}$ GT $(\mathbf{k g})$ & $\begin{array}{c}\mathbf{2 1}-\mathbf{3 0} \text { GT } \\
(\mathbf{k g})\end{array}$ \\
\hline 2014 & $1.659 .427,68$ & $2.307 .737,59$ \\
2015 & $3.233 .043,00$ & $5.555 .400,07$ \\
2016 & $1.213 .699,00$ & $3.648 .228,50$ \\
2017 & $2.622 .799,00$ & $5.482 .015,34$ \\
2018 & $4.619 .738,00$ & $8.191 .174,55$ \\
\hline
\end{tabular}

Sumber: Pelabuhan Perikanan Samudera Hindia (2019)

Berdasarkan tabel 3 di atas dapat dilihat bahwa jumlah hasil tangkap kapal ukuran di bawah 5GT berada di bawah hasil tangkap kapal dengan ukuran 21 - 30 GT. Berdasarkan tabel 3 di atas hasil tangkap ikan dengan kapal ukuran 5 GT dan ukuran 20 30 GT mengalami fluktuasi dari tahun 2014 sampai tahun 2018. Hasil tangkapan kapal ukuran di bawah 5 GT terendah terjadi pada tahun 2016, sedangkan hasil tangkap terendah kapal ukuran 20 - 30 GT berada di tahun 2014.

Penelitian yang dilakukan oleh Fauziyah, et al., (2011) menunjukkan bahwa dengan meningkatkan ukuran kapal maka hasil tangkapan akan ikut meningkat. Sementara menurut Ahmad \& Nofrizal (2015) terdapat kecenderungan produktivitas yang berbeda pada katerogi kapal nelayan skala kecil. Dalam penelitian tersebut variabel yang digunakan adalah hasil tangkap, jumlah trip dan ukuran kapal. Penelitian tersebut memiliki kekurangan karena belum memasukan jumlah $\mathrm{ABK}$, dan penggunaan BBM. Penelitian ini dapat melengkapi kekurangan dari penelitian terdahulu. Selain variabel jumlah ABK dan penggunaan $\mathrm{BBM}$, penelitian ini juga menganalisis perbedaan produktivitas antara kapal ukuran di bawah 5 GT dengan kapal ukuran 20 - 30 GT. 


\section{LITERATURE REVIEW}

Dalam penelitian ini, memerlukan penelitian terdahulu guna memperluas referensi yang terkait dengan analisis produktivitas kapal, hasil tangkapan, dan faktor-faktor yang mendukung dalam proses penangkapan ikan.

Penelitian yang dilakukan oleh Suradi, et al., (2011) bertujuan untuk mengkaji produktivitas dan kelayakan usaha Tuna Longline di Kabupaten Cilacap. Kesimpulannya adalah Jenis ikan yang dominan tertangkap kapal tuna longline yang didaratkan di PPS Cilacap adalah ikan Tuna dan Cakalang. Hasil tangkapan per trip (CPUE) ikan pelagis besar yang tertangkap kapal tuna longline berkisar antara 0,57 sampai dengan 4,26 ton/trip/tahun, dengan rata-rata 2,25 ton/trip/tahun. Produktivitas kapal tuna longline rata-rata sebesar 0,045 ton/GT/tahun. Berdasarkan kriteria NPV, IRR dan payback periods, usaha penangkapan ikan menggunakan tuna longline sudah tidak menguntungkan.

Penelitian yang dilakukan oleh Boesono, et al., (2016), bertujuan untuk menganalisis faktor faktor yang mempengaruhi berat total tangkapan dari mini purse seine dan menganalisis produktivitasnya. Berdasarkan berbagai faktor produksi yang digunakan sebagai variabel penduga diperoleh hasil bahwa, hanya variable bahan bakar kapal yang secara individual berpengaruh secara signifikan, tetapi secara bersamaan, semua variabel berpengaruh signifikan terhadap produksi ikan menggunakan mini purse seine

Penelitian yang dilakukan oleh Kisworo, et al., (2013), bertujuan untuk mengetahui hasil tangkapan rawai dasar (komposisi, produksi, dan nilai produksi), nilai hook rate dan produktivitas alat tangkap rawai dasar, dan kelayakan usaha (keuntungan, revenue cost ratio, payback period) rawai dasar dan diperoleh bahwa Semakin besar ukuran kapal hasil tangkap semakin besar namun semakin besar ukuran kapal nilai Produktivitas per tonnage semakin rendah.

Dalam perjalanannya hasil tangkap ikan nelayan di Kawasan PPSC mengalami fluktuasi di lima tahun terahir. Hasil tangkap ikan laut kapal ukuran di bawah 5 GT dan ukuran 21-30 GT Kawasan PPSC dapat dijelaskan bahwa ada perbedaan yang nyata antara hasil penangkapan ikan oleh kapal ukuran di bawah 5 GT dan kapal ukuran 21 - 30 GT. Perbedaan hasil tangkap ikan kapal ukuran di bawah 5 GT dengan kapal 21 - 30 GT tidak berbanding lurus dengan perbedaan ukuran kapal. Peneliti ingin menguji tingkat perbedaan produktivitas kapal tangkap ikan berukuran di bawah 5 GT dengan kapal tangkap ikan berukuran 21-30 GT dan ingin menguji pengaruh ukuran kapal, lama melaut, penggunaan $\mathrm{BBM}$, dan jumlah $\mathrm{ABK}$ terhadap hasil tangkap.

\section{KONSEP DASAR \\ Teori Produktivitas}

Penelitian ini akan meneliti terkait produktivitas kapal tangkap ikan di Kawasan PPSC. Menurut Fathoni (2017) pengertian dari produktivitas sendiri adalah suatu perbandingan antara hasil dari sutau pekerjaan atau output dengan keseluruhan sumberdaya atau input yang digunakan. Menurut Masharyono (2010) produktivitas dapat dijadikan metode alternatif untuk mengevaluasi kinerja yang telah dilakukan selain untuk evaluasi, produktivitas dapat digunakan sebagai alat untuk menilai efisiensi pemakaian sejumlah input dalam menghasilkan output tertentu.

\section{Teori Produksi}

Produksi merupakan suatu tindakan yang mengubah input menjadi suatu output. Dalam dunia ekonomi, produksi dinyatakan dalam fungsi produk, Fungsi produk menyatak berapa jumlah maksimum output yang dapat dihasilkan dari penggunaan sejumlah input dengan menggunakan teknogi yang dimiliki. Produksi merupakan kegiatan yang menciptakan nilai guna, nilai 
guna bararti kemampuan barang atau jasa yang dapat dimanfaatkan untuk memenuhi kebutuhan. Dalam kegiatan produksi, produsen membutuhkan faktor produksi. Arti faktor produksi adalah sumberdaya, sumber daya yang diambil dari alam (SDA) dan sumber daya yang disediakan oleh manusia yang dapat digunakan untuk memproduksi barang dan jasa (Manalu, 2017).

Menurut Sukirno (2009) fungsi dari produksi dapat di tuliskan dalam bentuk rumus sebagai berikut:

$\mathrm{Q}=\mathrm{f}(\mathrm{K}, \mathrm{L}, \mathrm{R}, \mathrm{T})$

Keterangan

Q = Jumlah output yang dapat di hasilkan

$\mathrm{K}=$ Stok modal

$\mathrm{L} \quad=$ Tenaga kerja

$\mathrm{R} \quad=$ Kekayaan alam

$\mathrm{T} \quad=$ teknologi

\section{METODE PENELITIAN}

Jenis Penelitian

Metode yang digunakan dalam penelitian ini adalah metode kuantitatif. Metode kuantitatif adalah Penelitian yang menekankan pada pengujian teori melalui pengukuran variabel penelitian dengan angka dan melakukan analisis data dengan prosedur statisik (Ratna,2015).

\section{Lokasi Penelitian}

Penelitian akan dilaksanakan di Pelabuhan Perikanan Samudera Cilacap ,Kecamatan Cilacap Selatan Kabupaten Cilacap pada bulan Mei tahun 2020.

\section{Populasi dan Sampel}

Populasi adalah keseluruhan yang di dalamnya terdiri dari obyek atau subyek yang memiliki kualitas dan karakteristik tertentu yang sebelumnya sudah ditetapkan dahulu oleh peneliti (Sugiyono,2012).

Populasi pada penelitian ini adalah masarakat nelayan Kota Cilacap.

\section{Analisis Produktivitas}

Produktivitas adalah rasio antara output dengan input. Produktivitas dapat digunakan untuk mengetahui sejauh mana ukuran kapal menentukan daya produksi nelayan. Untuk mengukur produktivitas menurut Marvin E memiliki perhitungan dapat digunakan rumus sebagai berikut (Masharyono, 2010):

\section{$\mathrm{IP}=(\mathrm{AOMP} / \mathrm{RIMP}) /(\mathrm{AOMB} / \mathrm{RIBP}) \mathrm{X}$ $100 \%$}

Keterangan :

IP = Indeks produktivitas

AOMP = Output agregat untuk periode yang diukur

$\mathrm{AOMB}=$ Output agregat untuk periode dasar

RIMP = Input agregat untuk periode yang diukur

RIBP = Input agregat untuk periode dasar

Setelah didapatkan nilai dari produktivitas maka dapat dilihat ukuran mana yang memiliki tingkat produktivitas dalam satu trip. Selanjutnya mencari hubungan antara hasil tangkap dengan ukuran kapal, lama melaut, penggunaan BBM, dan jumlah ABK.

\section{Analisis Regresi}

Analisis ini digunakan untuk mengetahui hubungan antara hasil tangkap dengan ukuran kapal, lama melaut, penggunaan BBM, dan jumlah ABK. Analisis regresi yang digunakan merupakan analisis regeresi linier. Dalam penelitian ini regresi linier berganda dibagi menjadi dua, yaitu regresi untuk kapal ukuran di bawah 5 GT dan kapal ukuran 20 - 30 GT. Berikut ini adalah bentuk dari analisis linier berganda yang di gunakan di dalam penelitian ini. 
$\mathrm{Y}_{1}=\alpha+\beta_{1} \mathrm{X}_{1}+\beta_{2} \mathrm{X}_{2}+\beta_{3} \mathrm{X}_{3}+\beta_{4} \mathrm{X}_{4}+\mu$

$$
\begin{aligned}
\text { Y1 } & : \text { Produksi } \\
\text { A } & : \text { Konstanta } \\
\beta & : \text { Koefisien } \\
\mathrm{X} 1 & : \text { Ukuran Kapal } \\
\mathrm{X} 2 & : \text { Lama melaut } \\
\mathrm{X} 3 & : \text { Penggunaan BBM } \\
\mathrm{X} 4 & \text { : Jumlah ABK } \\
\mu & : \text { Error term }
\end{aligned}
$$

\section{HASIL dan PEMBAHASAN}

Bagian ini menyajikan hasil dan diskusi mengenai produktivitas dan hubungan antara hasil tangkap dengan ukuran kapal, lama melaut, penggunaan BBM, dan Jumlah ABK.

\section{Produktivitas Berdasarkan Ukuran Kapal}

Berdasarkan hasil perhitungan produktivitas ukuran kapal di bawah 5 GT dan kapal ukuran 20 - 30 GT didapatkan hasil berupa tingkat produktivitas dari kapal ukuran di bawah 5 GT sebesar $2,07 \%$, Berikutnya hasil dari perhitungan produktivitas kapal ukuran 20 sampai 30 GT sebesar 6,95\%.

\section{Analisis Regresi}

Pada bagian ini hasil penelitian terbagi menjadi dua bagian, yaitu hasil dari regresi linier berganda kapal ukuran di bawah 5 GT dan kapal ukuran $20-30$ GT. Berdasarkan hasil analisis regresi linier berganda hasi yang didapatkan sebagai berikut.

\section{Hasil analisis linier berganda kapal ukuran 5 GT}

Berikut ini adala hasil uji $\mathrm{F}$ atau uji stimultan pada regresi linier berganda kapal ukuran di bawah 5 GT
Tabel 4. Hasil Uji Signifikansi Simultan (Uji F) Regresi Kapal Di Bawah 5 GT $\mathrm{F}$

Sig. 15,936

Sumber : Data Primer, 2020 (data diolah)

Berdasarkan Tabel 4, di ketahui bahwa secara bersama sama ukuran kapal, dan penggunaan $\mathrm{BBM}$, berpengaruh positif signifikan pada hasil tangkap nelayan yang menggunakan kapal dengan ukuran di bawah 5 GT.

Berikut ini adala hasil uji $\mathrm{T}$ atau uji parsial pada regresi linier berganda kapal ukuran di bawah 5 GT.

Tabel 5. Hasil Uji Parsial (Uji T) Regresi Kapal Ukuran Di Bawah 5 GT

\begin{tabular}{clcc}
\hline $\mathrm{N}$ & \multicolumn{1}{c}{ Model } & $\mathrm{T}$ & Sig. \\
\hline 1 & (Constant) & -1.535 & .132 \\
2 & ukuran kapal (X1) & 2.488 & .016 \\
3 & lama melaut (X2) & 1.699 & .096 \\
& penggunaan BBM & & \\
4 & (X3) & 2.365 & .022 \\
5 & jumlah ABK (X4) & -0.447 & .657 \\
\hline \multicolumn{3}{l}{ Sumber : Data Primer, 2020 (data diolah) }
\end{tabular}

Berdasarkan Tabel 5 diketahui jika masing masing variabel bebas memiliki hubungan yang berbeda beda. Pada nilai thitung variabel ukuran kapal sebesar 2,488 dengan tingkat signifikansi sebesar 0,016 pada derajat kepercayaan 95 persen dan nilai t-tabel sebesar 1,677. Dengan demikian ukuran kapal secara parsial berpengaruh positif signifikan terhadap hasil tangkap nelayan Kawasan PPSC. Selanjutnya nilai thitung variabel lama melaut sebesar 1,699 dengan tingkat signifikansi sebesar 0,096 pada derajat kepercayaan 95 persen dan nilai t-tabel sebesar 1,677. Dengan demikian lama melaut secara parsial berpengaruh positif terhadap hasil tangkap nelayan Kawasan PPSC. Variabel berikutnya adalah penggunaan BBM, nilai t-hitung variabel penggunaan $\mathrm{BBM}$ sebesar 2.365 dengan tingkat signifikansi sebesar 0,022 pada derajat kepercayaan 95 persen dan nilai ttabel sebesar 1,677. Dengan demikian 
penggunaan BBM secara parsial berpengaruh positif signifikan terhadap hasil tangkap nelayan Kawasan PPSC. Berikutnya variabel terakhir yaitu jumlah $\mathrm{ABK}$, nilai thitung variabel jumlah ABK sebesar -0,447 dengan tingkat signifikansi sebesar 0,657 pada derajat kepercayaan 95 persen dan nilai t-tabel sebesar 1,677. Dengan demikian penggunaan BBM secara parsial berpengaruh negatif terhadap hasil tangkap nelayan PPSC.

\section{DISKUSI}

\section{Produktifitas Kapal Tangkap Ikan}

Tingkat produktivitas kapal dengan ukuran kapal 5 GT sebesar 2,07\%. Hasil penelitian Fauziyah, Fitri Agustriani, dan Tuti Afridanelly (2011) yang mengatakan bahwa tingkat produktivitas disokong oleh besar ukuran GT kapal. Besar ukuran GT kapal turut menentukan seberapa banyak kapal tangkap ikan mampu menampung hasil tangkap.

\section{Pengaruh Ukuran Kapal Terhadap Hasil Tangkap Nelayan Kawasan PPSC}

Uji parsial yang dilakukan pada model regresi kapal ukuran di bawah 5 GT menunjukan bahwa ukuran kapal berpengaruh positif terhadap hasil tangkapan. Hasil uji ini selaras dengan penelitian yang di lakukan oleh Kisworo, dkk (2013). Penelitian Kisworo mengatakan bahwa ukuran kapal berpengaruh positif terhadap hasil tangkapan. Semakin besar ukuran kapal maka akan semakin banyak hasil tangkapan.

\section{Pengaruh Variabel Lama Melaut Terhadap Hasil Tangkap Nelayan PPSC}

Variabel lama melaut pada model regresi kapal ukuran di bawah 5 GT tidak berpengaruh terhadap hasil tangkap nelayan Kawasan PPSC. Hasil penelitian ini searah dengan hasil penelitian James Innes dan Pascoe (2008).
Pengaruh Variabel penggunaan BBM Terhadap Hasil Tangkap Nelayan PPSC

Variabel konsumsi BBM berpengaruh terhadap hasil tangkap nelayan. Berdasarkan hasil uji parsial pada model regresi kapal dengan ukuran di bawah 5 GT yang ditemukan peneliti menunjukan bahwa semakin banyak BBM yang di konsumsi membantu nelayan untuk dapat menangkap ikan lebih banyak, karena dengan jumlah BBM yang banyak nelayan dapat mencari ikan dari satu tempat ke tempat lainnya. Hal ini selaras dengan penelitian Boesono dkk (2016) yang menyatakan bahwa konsumsi BBM berpengaruh secara signifikan.

\section{Pengaruh Variabel Jumlah ABK Terhadap Hasil Tangkap Nelayan PPSC}

Variabel jumlah ABK tidak berpengaruh terhadap hasil tangkap nelayan yang menggunakan kapal di bawah 5 GT. Berubahnya jumlah ABK yang mencari ikan di dalam satu kapal tidak meningkatkan hasil tangkapan.

Setelah mendapatkan hasil regresi dari model regresi kapal ukuran di bawah 5 GT, berikutnya adalah hasil dari regresi kapal ukuran 20-30 GT. Berikut ini adalah hasil dari uji $\mathrm{F}$ atau uji stimultan dari regresi kapal kuran 20 - 30 GT.

Tabel 6. Hasil Uji Signifikansi Simultan (Uji F) Regresi Kapal 20 - 30 GT

\begin{tabular}{lr}
\hline F & 14,034 \\
Sig. & 0,000 \\
\hline \multicolumn{2}{c}{ Sumber : Data Primer, 2020 (data diolah) }
\end{tabular}

Sumber : Data Primer, 2020 (data diolah)

Berdasarkan uji stimultan regresi kapal ukuran 20 - 30 GT menunjukan bahwa variabel ukuran kapal, penggunaan BBM, dan jumlah ABK secara bersama sama berpengaruh positif signifikan terhadap hasil tangkapan. Setelah mengetahui pengaruh variabel bebas terhadap variabel terikat secara stimultan, berikut ini adalah hasil dari uji parsial variabel ukuran kapal, lama melaut, penggunaan $\mathrm{BBM}$, dan jumlah $\mathrm{ABK}$ 
terhadap hasil tangkap

Tabel 7. Hasil Uji Parsial (Uji T) Regresi Kapal Ukuran 20 - 30 GT

\begin{tabular}{|c|c|c|c|}
\hline No & Model & $\mathrm{T}$ & Sig. \\
\hline 1 & (Constant) & 2.825 & .008 \\
\hline 2 & $\begin{array}{l}\text { ukuran kapal } \\
\text { (X1) }\end{array}$ & 2.981 & .006 \\
\hline 3 & $\begin{array}{l}\text { lama melaut } \\
\text { (X2) }\end{array}$ & -1.903 & .067 \\
\hline 4 & $\begin{array}{l}\text { penggunaan } \\
\text { BBM (X3) }\end{array}$ & 2.373 & .024 \\
\hline 5 & $\begin{array}{l}\text { jumlah ABK } \\
\text { (X4) }\end{array}$ & 3.972 & .000 \\
\hline
\end{tabular}

Berdasarkan table 7 dapat kita lihat bahwa variabel ukuran kapal memiliki nilai $\mathrm{t}$ hitung sebesar 2,981 dengan tingkat signifikansi sebesar 0,006 pada derajat kepercayaan 95 persen dan nilai t-tabel sebesar 1,697, dengan begitu dapat dikatakan bahwa variabel ukuran kapal berpengaruh positif signifikan terhadap hasil tangkap nelayan. Berikutnya adalah variabel lama melaut, besar nilai $\mathrm{t}$ hitung sebesar $-1,903$ dan tingkat signifikansi 0,067 pada derajat kepercayaan 95 persen dan nilai t-tabel sebesar 1,697 maka dapat dikawakan bahwa variabel lama melaut berpengaruh negatif terhadap hasil tangkap. Variabel penggunaan BBM memiliki nilai hitung sebesar 2,373 dan tingkat signifikansi sebesar 0,24 pada derajat kepercayaan 95 persen dan nilai t-tabel sebesar 1,697 berarti variabel penggunaan BBM berpengaruh positif signifikan terhadap hasil tangkap. Terakhir variabel jumlah ABK dengan nilai t hitung sebesar 3,972 dan tingkat signifikansi 0,00 pada derajat kepercayaan 95 persen dan nilai t-tabel sebesar 1,697 di artikan bahwa jumlah ABK berpengaruh positif signifikan terhadap hasil tangkapan.

\section{DISKUSI}

\section{Produktifitas Kapal Tangkap Ikan}

Tingkat produktivitas kapal dengan ukuran kapal 20 - 30 GT sebesar 6,95\%. Hasil penelitian Fauziyah, Fitri Agustriani, dan Tuti Afridanelly (2011) yang mengatakan bahwa tingkat produktivitas disokong oleh besar ukuran GT kapal. Maka dapat di katakan semakin besar ukuran kapal akan semakin besar pula hasil tangkapannya dan lebih lanjut semakin banyak hasil tangkapannya maka akan semakin tinggi juga tingkat produktivitasnya.

\section{Pengaruh Ukuran Kapal Terhadap Hasil Tangkap Nelayan Kawasan PPSC}

Uji parsial yang dilakukan pada model regresi kapal ukuran 20 - 30 GT menunjukan bahwa ukuran kapal berpengaruh positif terhadap hasil tangkapan. Hasil uji ini selaras dengan penelitian yang di lakukan oleh Kisworo, dkk (2013). Penelitian Kisworo mengatakan bahwa ukuran kapal berpengaruh positif terhadap hasil tangkapan. Selain mampu menampung hasil tangkap yang lebih banyak, kapal dengan ukuran yang semakin besar dapat membantu nelayan untuk melaut lebih jauh karena kapal dengan ukuran yang besar akan lebih kuat, sehingga memungkinkan nelayan untuk menangkap ikan lebih jauh di laut.

\section{Pengaruh Variabel Lama Melaut Terhadap Hasil Tangkap Nelayan PPSC} Variabel lama melaut pada model regresi kapal ukuran 20 - 30 GT tidak berpengaruh terhadap hasil tangkap nelayan Kawasan PPSC. Hasil penelitian ini searah dengan hasil penelitian James Innes dan Pascoe (2008) .

\section{Pengaruh Variabel penggunaan BBM Terhadap Hasil Tangkap Nelayan PPSC}

Variabel konsumsi BBM berpengaruh terhadap hasil tangkap nelayan. Berdasarkan hasil uji parsial pada model regresi kapal dengan ukuran 20 - 30 GT yang ditemukan peneliti menunjukan bahwa semakin banyak BBM yang di konsumsi membantu nelayan untuk dapat menangkap ikan lebih banyak, karena penggunaan BBM yang lebih banyak 
berarti memungkinkan nelayan untuk mencari ikan lebih jauh lagi Hal ini selaras dengan penelitian Boesono dkk (2016) yang menyatakan bahwa konsumsi BBM berpengaruh secara signifikan.

\section{Pengaruh Variabel Jumlah ABK Terhadap Hasil Tangkap Nelayan PPSC}

Jumlah ABK berpengaruh positif signifikan terhadap hasil tangkap nelayan yang menggunakan kapal ukuran 20- 30 GT. Hal ini sesuai dengan penelitian Selfi Alhuda (2016), penelitian tersebut menyebutkan bahwa jumlah ABK turut berpengaruh pada hasil tagkap nelayan.

\section{KESIMPULAN}

Berdasarkan hasil penelitian dan pemaparan pada pembahasan mengenai produktivitas dan pengaruh ukuran kapal, lama melaut, penggunaan BBM, dan jumlah $\mathrm{ABK}$ terhadap hasil tangkap, dapat ditarik kesimpulan, yaitu:

1. Produktifitas kapal tangkap ukuran $20-$ 30 GT lebih besar dari produktivitas kapal tangkap ukuran di bawah 5 GT.

2. Variabel Ukuran kapal tangkap beru ukuran di bawah 5 GT dan kapal ukuran 20 - 30 GT berpengaruh positif signifikan terhadap hasil tangkap.

3. Variabel lama melaut kapal ukuran di bawah 5 GT berpengaruh positif tidak signifikan terhadap hasil tangkap. sedangkan variabel lama melaut pada kapal ukuran 20 - 30 GT berpengaruh negatif tidak signifikan.

4. Variabel konsumsi BBM pada kapal ukuran di bawah 5 GT dan kapal ukuran 20 - 30 GT berpengaruh positif signifikan hasil tangkap nelayan.

5. Variabel jumlah ABK pada kapal ukuran di bawah 5 GT berpengaruh negatif tidak signifikan pada hasil tangkap. Sedangkan variabel jumlah ABK pada kapal ukuran 20 - 30 GT berpegaruh positif signifikan

\section{Implikasi}

Berdasarkan pada kesimpulan yang telah dipaparkan, maka implikasi yang disampaikan adalah sebagai berikut:

1. Tingkat produktivitas kapal dengan ukuran kapal 5 GT sebesar 2,07\% sedangkan tingkat produktivitas kapal ukuran 20 - 30 GT sebesar 6,95\%. Jika prodiktivitas kapal dengan ukuran 20 - 30 GT lebih besar dari produktivitas kapal ukuran di bawah 5 GT maka nelayan yang masih menggunakan kapal ukuran di bawah 5 GT mengganti ukuran kapal menjadi ukuran 20 - 30 GT. Karena harga kapal ukuran 20 - 30 GT lebih mahal dari kapal ukuran di bawah 5GT maka sebaiknya nelayan yang menggunakan kapal ukuran di bawah 5 GT melakukan kerjasama dalam usaha penangkapan ikan yang nantiya hasil usaha tersebut dapau digunakan untuk membeli kapal ukuran 20 - 30 GT, sehingga produktivitasnya dapat meningkat.

2. Ukuran kapal berpengaruh positif signifikan terhadap hasil tangkapan. Dengan ukuran GT kapal yang besar dapat meningkatkan jumlah hasil tangkapan. Apabila nelayan yang menggunakan kapal dengan ukuran di bawah 5 GT ingin meningkatkan hasil tangkapnya maka mereka harus menggunakan kapal dengan GT yang lebih besar lagi. Bantuan pemerintah berupa penetapan harga kapal dapat membantu nelayan yang masih menggunakan kapal di bawah 5 GT agar dapat membeli kapal dengan ukuran yang lebih besar dengan harga yang tidak terlalu tinggi, dengan begitu hasil tangkap dapat meningkat. Jika nelayan yang menggunakan kapal ukuran 20 - 30 GT ingin meningkatkan hasil tangkapannya maka nelayan harus mengganti ukuran kapal tersebut dengan ukuran GT yang lebih besar, hal ini dapat dilakukan dengan menyisihkan pendapatan hasil menangkap ikan dan membeli kapal dengan ukuran yang lebih besar.

3. Pada ukuran kapal di bawah 5 GT lama melaut berpengaruh positif tidak signifikan terhadap hasil tangkap, sedangkan pada ukuran kapal 20 - 30 GT berpengaruh negatif tidak signifikan 
terhadap hasil tangkap. Jika lama melaut berpengaruh positif tidak signifikan terhadap hasil tangkap maka nelayan yang menggunakan kapal dengan ukuran di bawah 5 GT harus menggunakan waktu dengan se efisien mungkin. Salah satu caranya adalah dengan menentukan lokasi penangkapan, dimana lokasi tersebut terdapat banyak ikan yang menjadi target penangkapan. Begitu halnya dengan nelayan kapal 20 - 30 GT, jika lama melaut pada kapal $20-30$ GT berpengaruh negatif tidak signifikan terhadap hasil tangkap, maka nelayan Kapal 20 - 30 GT dapat mengurangi waktunya dalam melaut dan memilih lokasi penangkapan yang lebih cermat. Lokasi yang di maksut berupa rumpon, dengan memanfaatkan rumpon nelayan yang menggunakan kapal dengan ukuran 20 - 30 GT dapat menggunakan waktu lebih efisien.

4. Konsumsi BBM berpengaruh positif signifikan terhadap hasil tangkap nelayan kapal dengan ukuran di bawah 5 GT dan kapal ukuran 20 - 30 GT. Jika dengan menambah tingkat konsumsi BBM dapat mendorong hasil tangkap yang lebih banyak maka nelayan menambah tingkat konsumsi BBM yang nantinya akan di gunakan untuk mecari lokasi lokasi penangkapan ikan yang dinilai cukup banyak target tangkapan, dengan begitu di lain waktu, nelayan dapat langsung menuju lokasi tersebut sehingga menghemat waktu penangkapan.

5. Jumlah ABK berpengaruh negatif tidak signifikan terhadap hasil tangkap nelayan Kawasan PPSC yang menggunakan kapal ukuran di bawah 5 GT. Sedangkan kapal dengan ukuran 20 - 30 GT, jumlah ABK dalam satu kapal berpengaruh postif signifikan. Jika pada kapal di bawah 20 30 manambah jumlah ABK dalam satu kapal memberikan peningkatan hasil tangkapan, maka jumah ABK pada kapal ukuran di bawah 5 GT tidak perlu menambah jumlah ABK karena walaupun menambah jumlah ABK tapi hasil tangkap yang didapat tidak mengalami perubahan yang berarti, sebaiknya nelayan yang menggunakan kapal ukuran di bawah 5 GT mengalokasikan biaya tersebut digunakan untuk membeli keperluan pemeliharaan kapal dan mesin kapal, agar kapal dapat tetap melaut dalam kondisi yang baik dan mengurangi resiko kerusakan kapal dan mesin kapal saat menangkap ikan.

\section{DAFTAR PUSTAKA}

Ahmad, M., \& Nofrizal (2015). Economic Efficiency and Productivity of the Fishing Boat for Giant Threadfish (Eletheronema

Tetradactylum). Jurnal Ilmu dan Teknologi Kelautan Tropis, 7(1).

Alhuda, S., \& Rustikawati, I. (2016). Analisis produktivitas dan kinerja usaha nelayan purse seine di Pelabuhan Perikanan Pantai Lempasing, Bandar Lampung. Jurnal Perikanan Kelautan, 7(1). 30 $-40$

Ardiansyah, M., Suharno, \& Susilowati, I. (2019). Estimating the conservation value of mangrove forests in marine protected areas: special reference to Karimunjawa waters, Indonesia. Aquaculture, Aquarium, Conservation \& Legislation, 12(2), 437-447.

Boesono, H., Setiawan, D. R., Prihantoko, K. E., Jayanto, B. B., \& Malala, A. R. (2016). Productivity analysis of mini purse seine in PPI Pulolampes Brebes, Central Java, Indonesia. Aquatic Procedia, 7, 112-117.

Durand, S. S. (2010). Studi potensi sumberdaya alam di kawasan pesisir Kabupaten Minahasa selatan. Jurnal Perikanan Dan Kelautan Tropis, 6(1), 1-7.

Fathoni, K., \& Ghozali, M. (2017). Analisa Konsep Produktivitas Kerja Konvensional Dalam Pandangan Islam. Al Tijarah, 3(1), 1-14.

Fauziyah, F., Agustriani, F., \& Afridanelly, T. (2011). Model Produktivitas Hasil 
Tangkapan Bottom Gillnet di Pelabuhan Perikanan Nusantara (PPN) Sungailiat Provinsi Bangka Belitung. Jurnal Penelitian Sains, 14(3).

Innes, J., \& Pascoe, S. (2008). Productivity impacts of veil nets on UK Crangon vessels. Journal of Agricultural Economics, 59(3), 574-588.

Kisworo, R., Saputra, S. W., \& Ghofar, A. (2013). Analisis Hasil Tangkapan, Produktivitas, dan Kelayakan Usaha Perikanan Rawai Dasar di PPI Bajomulyo I Kabupaten Pati. Journal of Management of Aquatic Resources, 2(3), 190-196.

Manalu, E., Sianturi, F. A., \& Manalu, M. R. (2017). Penerapan Algoritma Naive Bayes Untuk Memprediksi Jumlah Produksi Barang Berdasarkan Data Persediaan Dan Jumlah Pemesanan Pada Cv. Papadan Mama Pastries. Jurnal Mantik Penusa, 1(2).

Masharyono, I. S. (2010). Analisis Pengukuran Produktivitas Dengan Model The American Productivity Center (Apc) Dan Marvin E. Mundel (Studi Kasus pada Bagian Pabrikasi PG. Madubaru Madukismo). Jurnal Inovasi Industri, 24.

Masharyono, I. S., \& Syukri, S. H. A (2010). Analisis Pengukuran Produktivitas Dengan Model The American Productivity Center (Apc) Dan Marvin E. Mundel, 1, 23-31.

Pribadi, B. (2018). Statistik Perikanan 2018. Cilacap, 1.

Ratna Wijayanti Daniar Paramita. (2015). Metode Penelitian Kuantitatif (Edisi 1). Lumajang: STIE WIDYA GAMA. Diakses dari http://repository.stiewidyagamaluma jang.ac.id/102/

Sukirno, Sadono. (2009). Mikro Ekonomi Teori Pengantar (edisi 3). Jakarta: PT Rajagrafindo Persada. 195

Sugiyono. (2012). Statistika Untuk Penelitian. Bandung: Alfa Beta, CV. 61
Suharno, Anwar, N., \& Saraswati, E. (2018). Do fishers need to diversify their source of income? A special reference in vulnerable fishers of Cilacap Waters, Indonesia. Aquaculture, Aquarium, Conservation \& Legislation, 11(5), 1605-1615.

Suharno, Widayati T., (2015). Management policies for small-scale fishers in the north coast of Central Java. Proceeding SENDI_U. UNISBANK, 1-8.

Susilowati, I., Syah, A. F., Suharno, S., \& Aminata, J. (2018). Economic valuation of tourism attraction of jatijajar cave in Kebumen Regency. JEJAK: Jurnal Ekonomi dan Kebijakan, 11(1), 12-28.

Suradi WS, S. W., Solichin, A., Wijayanto, D., \& Kurohman, F. (2011) Produktivitas Dan Kelayakan Usaha Tuna Longline Di Kabupaten Cilacap Jawa Tengah. Saintek Perikanan. 84. 